OPEN ACCESS

Edited by:

Franziska Degé

Justus-Liebig-University, Germany

Reviewed by:

Sylvain Moreno,

University of Toronto/Baycrest

Hospital, Canada

Laura Marie Getz,

University of Virginia, USA

*Correspondence:

E. Glenn Schellenberg,

Department of Psychology, University

of Toronto Mississauga, 3359

Mississauga Rd. North, Mississauga,

ON L5L 1C6, Canada

g.schellenberg@utoronto.ca

Specialty section:

This article was submitted to Cognition, a section of the journal

Frontiers in Psychology

Received: 14 July 2014

Accepted: 26 February 2015

Published: 24 March 2015

Citation:

Corrigall $K A$ and Schellenberg $E G$

(2015) Predicting who takes music

lessons: parent and child

characteristics. Front. Psychol. 6:282

doi: 10.3389/fpsyg.2015.00282

\section{Predicting who takes music lessons: parent and child characteristics}

\author{
Kathleen A. Corrigall ${ }^{1}$ and E. Glenn Schellenberg ${ }^{2 *}$ \\ ${ }^{1}$ Department of Psychology, MacEwan University, Edmonton, AB, Canada, ${ }^{2}$ Department of Psychology, University of Toronto \\ Mississauga, Mississauga, ON, Canada
}

Studies on associations between music training and cognitive abilities typically focus on the possible benefits of music lessons. Recent research suggests, however, that many of these associations stem from niche-picking tendencies, which lead certain individuals to be more likely than others to take music lessons, especially for long durations. Because the initial decision to take music lessons is made primarily by a child's parents, at least at younger ages, we asked whether individual differences in parents' personality predict young children's duration of training. Children between 7 and 9 years of age $(N=170)$ with varying amounts of music training completed a measure of IQ. Their parents provided demographic information as well as ratings of their own and their child's Big Five personality dimensions. Children's personality traits predicted duration of music training even when demographic variables and intelligence were held constant, replicating findings reported previously with 10- to 12-year-olds and 17-year-olds. A novel finding was that parents' openness-to-experience predicted children's duration of training, even when characteristics that pertained to children (demographic variables, intelligence, and personality) were controlled statistically. Our findings are indicative of passive and active gene-environment correlations, whereby genetic predispositions influence the likelihood that a child will have certain experiences, such as music training.

Keywords: music training, music lessons, cognition, personality, individual differences, gene-environment interaction

\section{Introduction}

What kinds of parents choose to enroll their children in music lessons, and how do children who take music lessons differ from their peers? Typically, parents take primary responsibility for the decision to enroll young children in an extracurricular activity. As children grow up and become more independent, they gain more control over choosing their activities-deciding whether to continue pursuing their current extracurricular activities or to pursue new interests. To date, most research has focused on associations between music training and non-musical abilities in the interest of exploring the potential benefits of music training. The present investigation, by contrast, asked whether pre-existing individual differences determine who takes music lessons. In other words, we asked how genes interact with the environment.

Until recently, few studies examined factors that influence the likelihood of taking music lessons or developing musical expertise, and most of the available research was conducted with adults rather than children. Adults who achieve high levels of musical expertise differ from less accomplished musicians in terms of greater levels of passion for music, enhanced music aptitude, and 
more practice (e.g., Ericsson et al., 1993; Ruthsatz et al., 2008; Bonneville-Roussy et al., 2011; Macnamara et al., 2014). In fact, practice is the best predictor that children and adolescents will continue playing music into adulthood (Theorell et al., 2015). Practice is also associated with the propensity to experience musical flow, which is defined as being completely absorbed and focused on an activity that one enjoys (Butkovic et al., 2015). Importantly, most of these individual differences appear to be genetically influenced, including music aptitude (Drayna et al., 2001; Ukkola et al., 2009; Park et al., 2012; Ukkola-Vuoti et al., 2013; Mosing et al., 2014; Tan et al., 2014), musical achievement (Hambrick and Tucker-Dobb, 2015), musical flow (Butkovic et al., 2015), and even practice (Mosing et al., 2014; Butkovic et al., 2015; Hambrick and Tucker-Dobb, 2015). These findings suggest those who are most involved with and skilled at music may be naturally inclined to seek out environments that match their predispositions.

Demographic variables also play a role. Compared to musically untrained individuals, those who take music lessons tend to come from families with higher socioeconomic status (SES; Sergeant and Thatcher, 1974; Schellenberg, 2006, 2011a,b; Corrigall et al., 2013; Müllensiefen et al., 2014), and to have greater involvement in non-musical extracurricular activities (Schellenberg, 2006, 2011a; Corrigall et al., 2013). In short, children who take music lessons tend to have parents who can afford to pay for the lessons and for other extracurricular activities. High-SES parents may also place greater value on learning opportunities outside of regular school, and therefore support children's continued participation in extracurricular activities.

Music training, expertise, and practice are all associated with openness-to-experience, a Big Five trait that involves an interest in the arts, intellectual curiosity, and a tendency to try new activities and learn various skills, including how to play a musical instrument (Dyce and O'Connor, 1994; Gillespie and Myors, 2000; Corrigall et al., 2013; Hille and Schupp, 2014; Müllensiefen et al., 2014; Butkovic et al., 2015). Because personality traits are also genetically influenced (Matthews et al., 2003; Bouchard, 2004), these findings are consistent with the idea that certain individuals are more likely to take music lessons in the first place and to continue their involvement in music, such that these experiences allow them to become highly skilled. More generally, individuals who are high in openness-to-experience seek out experiences that help them learn new skills, a gene-environment interaction that ultimately enhances cognitive functioning and achievement (Dollinger and Orf, 1991; McCrae, 1993; Harris, 2004; Moutafi et al., 2006; John et al., 2008).

The prevailing view, however, is that music lessons enhance non-musical abilities such as speech perception (Strait and Kraus, 2011), working memory (George and Coch, 2011), and executive functions (Bialystok and DePape, 2009; Moradzadeh et al., 2014), with little to no consideration of pre-existing individual differences that influence who takes music lessons in the first place. This view has filtered down to the general public. For example, when parents are asked why it is important for their children to have music training, they often mention cognitive benefits such as improving intelligence and academic performance (Dai and Schader, 2001; Mehr, 2014). Indeed, it is well-documented that music training is associated positively with many cognitive skills (see Costa-Giomi, 2012; Schellenberg and Weiss, 2013 for reviews). Because the vast majority of these findings came from studies with correlational or quasi-experimental designs, the view that music training is causing the associations represents a logical mistake of inferring causation from correlation, while ignoring the role of pre-existing differences in cognitive abilities, personality, music aptitude, and demographic background (Schellenberg, 2015).

Some researchers (e.g., Ho et al., 2003; Forgeard et al., 2008; George and Coch, 2011; Strait and Kraus, 2011) argue that associations between duration of music training and non-musical abilities constitute evidence for a dose-dependent benefit-the longer the training, the greater the improvement, even though preexisting differences (re: cognition, personality, demographics) undoubtedly play a role in determining who takes music lessons for years on end (Corrigall et al., 2013). Correlations between age of onset of music training and task performance (or brain structure or function) are similarly interpreted as evidence for greater plasticity at younger ages (e.g., Habib and Besson, 2009; Penhune, 2011), even though children who begin music lessons at young ages are likely to differ systematically from other children. Finally, in longitudinal quasi-experiments, lack of evidence for an association at pre-test (Norton et al., 2005) does not guarantee that associations at post-test (Hyde et al., 2009) are solely the consequence of learning and the environment. Early in development, genetically determined behaviors and characteristics may not be evident phenotypically.

It is well-documented that the influence of genes on the environment changes as children develop (Plomin et al., 1977; Scarr and McCartney, 1983; Plomin, 2014). Such influences are initially passive, when the parents' genotype (related to the child's genotype) determines the environment in which a child is raised. As the child develops, the genetic influence becomes evocative: children's predispositions influence how others respond to them. As children age further, they start to play an active role, seeking out environments that match who they are, a process called "niche-picking."

Corrigall et al. (2013) recruited a large sample of 10- to 12 -year-olds and reported that duration of music training was associated positively with SES, intelligence, and participation in non-musical extracurricular activities, as well as with two personality traits: conscientiousness and openness-to-experience. Associations between music training and conscientiousness, and between music training and openness, were also evident in study of 17-year-olds (Hille and Schupp, 2014). These findings are consistent with an active gene-environment correlation: Bright, curious, and motivated individuals seek out intellectually enriching activities-including but not limited to music lessons-that are likely to make them even more bright, curious, and motivated. Because passive genetic effects play a larger role at younger ages, one would expect that parents' characteristics would more strongly influence whether younger children take music lessons.

In the present investigation, we tested this prediction in a group of 7- to 9-year-olds, who are at the age when traditional music lessons (i.e., private instrumental training such as 
piano lessons) typically begin. The children were administered a standardized measure of intelligence. Their parents provided demographic information as well as ratings of their child's and their own personalities. Demographic, cognitive, and personality variables were used in regression analyses to predict duration of music training. We expected to replicate findings that children's own characteristics (such as their cognitive abilities and personalities) predict the environments they experience, in this case music training (Corrigall et al., 2013; Degé et al., 2014; Hille and Schupp, 2014). Because our sample comprised children younger than those tested previously, we also expected parents' personalities to predict their children's duration of music training.

\section{Method}

The study protocol was approved by the Research Ethics Board at the University of Toronto.

\section{Participants}

We recruited 1707 - to 9 -year-olds ( 88 girls, 82 boys, mean age 8.6 years, $S D=0.8$ years) from the local community. Children received a gift certificate as appreciation for participating. Descriptive statistics are provided in Table $\mathbf{1}$.

\section{Outcome Variable}

The outcome variable was cumulative months of extracurricular music lessons (i.e., individual or group lessons outside of the regular school curriculum). Duration of training was summed for

TABLE 1 | Descriptive statistics for outcome and predictor variables.

\begin{tabular}{lrr}
\hline Variable & $\boldsymbol{M}$ & SD \\
\hline Cumulative duration of music training in months & 13.3 & 17.7 \\
Age in years & 8.6 & 0.8 \\
Family income & 5.6 & 2.1 \\
Parents' education & 5.5 & 1.6 \\
Cumulative duration of non-musical activities in months & 46.8 & 39.4 \\
IQ & 111.1 & 12.9 \\
Average grade & 8.7 & 1.2 \\
Openness (C) & 5.3 & 0.9 \\
Conscientiousness (C) & 4.6 & 0.8 \\
Extraversion (C) & 5.0 & 0.7 \\
Agreeableness (C) & 4.9 & 0.8 \\
Neuroticism (C) & 3.6 & 0.8 \\
Openness (P) & 3.5 & 0.6 \\
Conscientiousness (P) & 4.1 & 0.6 \\
Extraversion (P) & 3.6 & 0.8 \\
Agreeableness (P) & 4.1 & 0.5 \\
Neuroticism (P) & 2.6 & 0.7 \\
\hline
\end{tabular}

Family income was measured on a 9-point scale in increments of \$25,000 (1 = less than $\$ 25,000 ; 2=\$ 25,000-\$ 49,999 ; 3=\$ 50,000-\$ 74,999$; and so on). Parents' education was measured on an 8 -point scale ( $1=$ did not finish high school, $8=$ graduate degree). Average grade was measured on a 12-point scale (where the highest grade $=12$ and a failing grade $=0$ ). Child personality traits were measured on 7-point scales and parent personality traits were measured on 5-point-scales in which higher scores indicate stronger trait tendencies. C, child; $P$, parent. children who took both individual and group lessons, or who took lessons on two different instruments at the same time (e.g., a child who took both piano and violin lessons for 9 months simultaneously was considered to have 18 months of music training). For those with some training $(n=98)$, duration ranged from 0.5 to 88 months ( $M=23.0$ months; $S D=17.8$ months), and $65 \%$ were still taking lessons at the time of the study $(n=64)$.

\section{Predictor Variables}

Annual family income was measured on a 9-point scale $(1 \leq$ $\$ 25,000,9 \geq \$ 200,000$; Canadian dollars, data missing for four children). The modal income was $4(\$ 75,000-\$ 100,000)$; the median was $5(\$ 100,000-\$ 125,000)$. Parents' education was measured on an 8-point scale $(1=$ did not finish high school, $8=$ graduate degree). For both mothers and fathers, the modal and median response was 6 (university graduate), and responses were averaged across parents for subsequent analyses. Because music training also tends to be associated with involvement in other extracurricular activities (Schellenberg, 2006, 2011a; Corrigall et al., 2013), we collected information about participation in activities such as sports and arts other than music. Duration of involvement was summed as for music training. On average, children had 46.8 cumulative months of involvement in non-musical activities ( $S D=39.4$ months).

Children were administered the two-subtest version of the Wechsler Abbreviated Scale of Intelligence (WASI; Wechsler, 1999). As in previous research with middle-class Canadian children (Schellenberg, 2006, 2011a; Corrigall et al., 2013), the average IQ $(M=111.1, S D=12.9)$ was substantially higher than American norms, $t_{(169)}=11.21, p<0.001$. Parents of $92 \%$ of the sample (157 children) provided photocopies of school report cards. In the province of Ontario, report cards for publicly funded schools have a standardized format in which grades are reported on the same scale. Children's grades were converted to a 12 point numerical scale (where the highest grade $=12$ and a failing grade $=0)$ and averaged across school subjects $(M=8.69$, $S D=1.18$ ).

To measure children's personality, a parent completed the short version of the Inventory of Children's Individual Differences (ICID-S; Deal et al., 2007). Parents also provided selfreports of their own personality using the Big Five Inventory (BFI; John et al., 1991). Although parents' personality scores were significantly correlated with the scores they provided for their children (with the exception of conscientiousness), the weak to moderate correlations ( $r$ r ranged between 0.084 and 0.325 , see Table 2) confirmed that parents made a distinction between their personalities and those of their children.

\section{Procedure}

Children were administered the WASI by a trained research assistant. A parent completed a demographics questionnaire, the ICID-S as it pertained to the child, and the BFI as self-report.

\section{Results}

Pairwise correlations among the predictor variables are provided in Table 2. The principal analyses examined associations between 


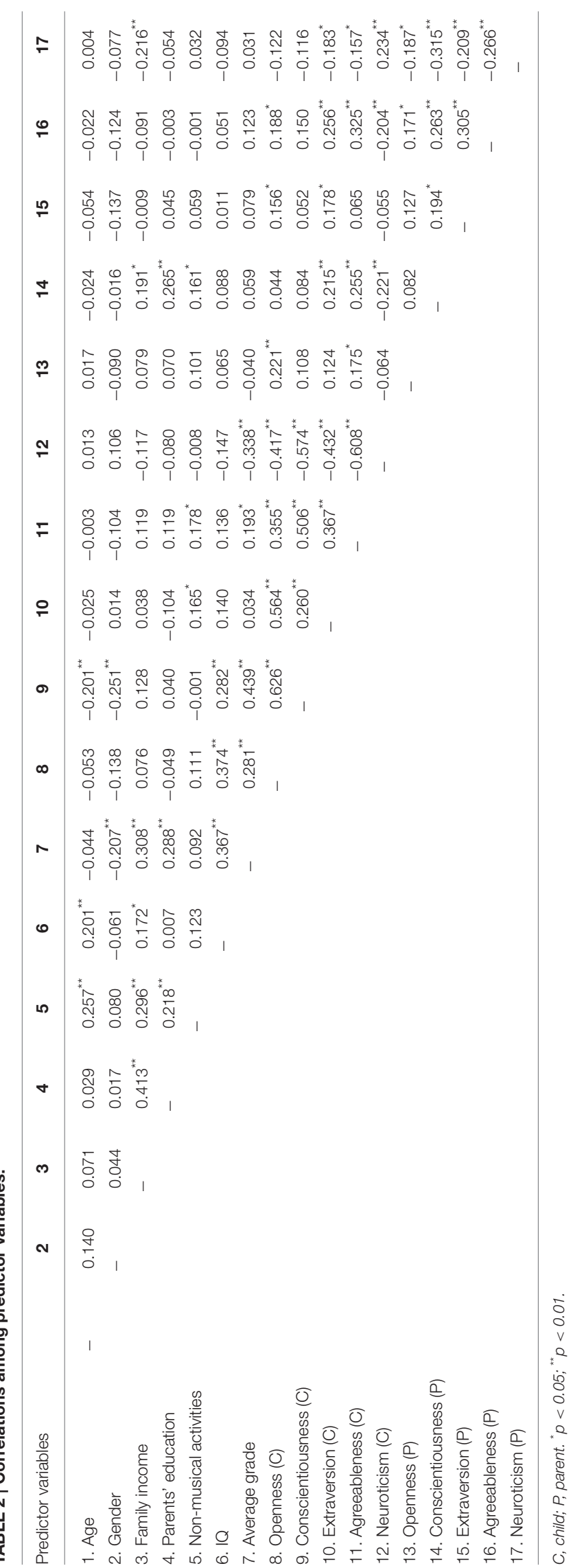

the outcome variable (duration of music training) and the predictor variables. Preliminary inspection of scatterplots indicated no violations of linearity. Pairwise correlations revealed that children who took music lessons for longer durations tended to be older, $r=0.20, N=170, p=0.008$, to come from families with higher incomes, $r=0.23, N=166, p=0.003$, to have parents with more education, $r=0.15, N=170, p=0.006$, and to be more involved in non-musical activities, $r=0.19$, $N=170, p=0.013$. They also tended to have higher IQs, $r=0.21, N=170, p=0.006$, and to be more open-toexperience, $r=0.24, N=170, p=0.002$, and agreeable, $r=0.25, N=170, p=0.001$, but less neurotic, $r=-0.15$, $N=170, p=0.045$. Finally, children with more music training had parents who were more open-to-experience, $r=0.30$, $N=170, p<0.001$. In absolute terms, this final association was the strongest we observed.

Identification of pairwise associations between duration of music training and several predictor variables motivated further analyses to determine which of these predictors had significant partial associations with duration of training. Hierarchical multiple regression was used with duration of music training as the outcome variable. Predictor variables were those that had simple associations with duration of music training (Table 3). Demographic variables (age, family income, parent's education, and duration of non-musical activities) and IQ were entered on the first step, which together accounted for $11.4 \%$ of the variance in duration of music training (adjusted $R^{2}=0.086$ ). Partial correlations revealed that age, family income, and IQ were marginally significant predictors $(p s<0.10)$. Thus, the association between duration of music training and IQ was near-significant when demographic variables were held constant, although it was weaker than in previous correlational studies with older children (Schellenberg, 2006, 2011a; Corrigall et al., 2013) and in a quasi-experiment with same-age children (Schellenberg and Mankarious, 2012).

We added children's personality variables (openness-toexperience, agreeableness, and neuroticism) on the second step to examine whether personality traits helped to explain duration of music training when demographic and cognitive variables were held constant. Children's personality accounted for an additional $5.9 \%$ of the variance in duration of music training, $F_{\mathrm{inc}(3,157)}=$ $3.76, p=0.031$, with the new model accounting for $17.3 \%$ of the variance in duration of music lessons (adjusted $R^{2}=0.131$ ). Age and the child's agreeableness were significant predictors, whereas family income and the child's openness-to-experience made marginal contributions. As in previous research (Corrigall et al., 2013), accounting for personality variables in addition to demographic variables rendered the association between IQ and duration of music training non-significant.

On the third step, parents' personality (openness-toexperience) was added to the model to examine whether parent characteristics helped to explain how long their children took music lessons when variables that pertain to the child (demographics, cognitive ability, personality) were held constant. The addition of parents' openness-to-experience improved explanatory power by an additional $4.7 \%, F_{\text {inc }(1,156)}=9.42$, $p=0.003$, such that the model now accounted for $22.0 \%$ of the 
TABLE 3 | Results from hierarchical multiple regression with duration of music training as the outcome variable.

\begin{tabular}{|c|c|c|}
\hline Predictor & Partial correlation (pr) & $p$-value \\
\hline \multicolumn{3}{|c|}{ Step 1: $R=0.337$, adjusted $R^{2}=0.086, F_{(5,160)}=4.10, p=0.002$} \\
\hline Age & 0.13 & 0.093 \\
\hline Family income & 0.14 & 0.083 \\
\hline Parents' education & 0.06 & 0.457 \\
\hline Non-musical activities & 0.08 & 0.323 \\
\hline IQ & 0.15 & 0.063 \\
\hline \multicolumn{3}{|c|}{ Step 2: $R=0.416$, adjusted $R^{2}=0.131, F_{(8,157)}=4.11, p<0.001$} \\
\hline Age & 0.17 & 0.029 \\
\hline Family income & 0.14 & 0.082 \\
\hline Parents' education & 0.07 & 0.414 \\
\hline Non-musical activities & 0.02 & 0.770 \\
\hline IQ & 0.06 & 0.441 \\
\hline Child's openness-to-experience & 0.14 & 0.084 \\
\hline Child's agreeableness & 0.17 & 0.031 \\
\hline Child's neuroticism & 0.05 & 0.498 \\
\hline \multicolumn{3}{|c|}{ Step 3: $R=0.469$, adjusted $R^{2}=0.175, F_{(9,156)}=4.90, p<0.001$} \\
\hline Age & 0.17 & 0.029 \\
\hline Family income & 0.13 & 0.093 \\
\hline Parents' education & 0.06 & 0.461 \\
\hline Non-musical activities & 0.02 & 0.838 \\
\hline IQ & 0.07 & 0.384 \\
\hline Child's openness-to-experience & 0.10 & 0.228 \\
\hline Child's agreeableness & 0.15 & 0.070 \\
\hline Child's neuroticism & 0.03 & 0.702 \\
\hline Parent's openness-to-experience & 0.24 & 0.003 \\
\hline
\end{tabular}

variance in duration of training (adjusted $R^{2}=0.175$ ). Age and parents' openness-to-experience made significant contributions, and family income and children's agreeableness made marginal contributions.

\section{Discussion}

We examined whether duration of music training was associated with demographic, cognitive, and personality variables in a large sample of 7- to 9-year-old children. We hypothesized that at these young ages, parental characteristics would be associated with children's duration of training. As duration of training increased, so did SES, IQ, and involvement in non-musical extracurricular activities. Duration of training was also associated positively with children's openness-to-experience and agreeableness, negatively with children's neuroticism, and positively with the parents' openness-to-experience. The sheer number of association confirms that children who take music lessons differ from other children in many respects.

As in an earlier study (Corrigall et al., 2013), children's personality predicted duration of music training even after demographic and cognitive abilities were held constant, but the association between music training and intelligence disappeared when demographic variables and personality were statistically controlled. Because individual differences in personality are strongly heritable (Bouchard, 2004), the present findings considered jointly with the earlier results point to gene-environment interactions, in which the child's role becomes increasingly active over development (Scarr and McCartney, 1983). Early in development, the parents' openness-to-experience is the principle factor determining whether their children take music lessons, consistent with passive genetic influences. At this point, the children's agreeableness matters most, because they must agree to go along with their parents' decision. For older children who are more independent, their own level of openness-to-experience is the principal factor that determines whether they continue taking lessons. Throughout this process, music lessons are an environmental factor that is consistent with the child's predispositions, which are, in turn, reinforced and enhanced by the environment.

In the earlier study, an association between duration of music training and conscientiousness in 10- to 12-year-olds explained why musically trained children do better in school than one would predict based on IQ (Corrigall et al., 2013). Musically trained 10- to 12-year-olds are particularly hard-working, diligent, and self-disciplined, traits that facilitate performance in school. In the present sample of 7- to 9-year-olds, duration of music training was not associated with children's conscientiousness or with their average grade in school. One possibility is that conscientiousness influences children's tendency to persist at music lessons, but not whether they take lessons in the first place or begin lessons early in life. As such, children in our sample may have been too young for conscientiousness to exert much influence. Rather, duration of training at this age was associated with higher levels of agreeableness and lower levels of neuroticism. Because young children's participation in extracurricular activities is controlled primarily by their parents, these associations could reflect children's tendency to be cooperative and compliant (related to agreeableness), and "easy-going" rather than hostile, anxious, and impulsive (related to neuroticism). It is also possible that we found a different pattern of associations because children's personality traits were more strongly inter-correlated (see Table 2) than they were for the older children tested by Corrigall et al. (2013). In general, personality traits become more distinct as children develop (e.g., Caspi et al., 2005; Soto et al., 2008).

Why is openness-to-experience the best overall predictor of music training, whether it comes from the child or the parent? One obvious reason is that part of openness-to-experience is aesthetic sensitivity (i.e., liking and appreciating music, art, and dance). Openness is also associated with creativity (McCrae, 1987), intelligence (McCrae, 1993; Harris, 2004; Moutafi et al., 2006), academic achievement (Dollinger and Orf, 1991; John et al., 2008), and an interest in and enjoyment of intellectual activities (Furnham et al., 2008). It is associated with variation in two genes involved in dopaminergic function in the prefrontal cortex (DeYoung et al., 2011). The prefrontal dopamine system is known to be associated with working memory (e.g., Braver and Cohen, 2000; Robbins, 2005), learning about rewards (Schultz, 
2006), and motivation to understand or know the answer to a question (Panksepp, 1998).

As noted, there is a genetic component to music-specific abilities (Tan et al., 2014), including the perception of tonality (Drayna et al., 2001) and music aptitude (Ukkola et al., 2009; Park et al., 2012; Ukkola-Vuoti et al., 2013). Although expert levels of performance have been claimed to be a consequence of deliberate practice (Ericsson et al., 1993), empirical evidence indicates that that role of practice accounts for only $21 \%$ of the variance in music performance (Macnamara et al., 2014). Moreover, music practice has a large genetic contribution (38\%), as does musical accomplishment (26\%), and the genetic component to accomplishment is largely independent of the genetic component to practice (Hambrick and Tucker-Dobb, 2015). Finally, each Big Five personality dimension has a heritability estimate of approximately 50\%, whereas heritability estimates of IQ increase steadily during development, reaching a high of over $80 \%$ in adulthood (Bouchard, 2004). In short, music training is unlikely to have large and systematic non-musical benefits that are consistent across individuals regardless of their genetic make-up.

Research on music training should be considered within the cultural context in which it takes place-namely, Western cultures. Because learning to play music in the Western world typically involves relatively costly individual lessons taken outside of school, training on an expensive instrument (e.g., piano), and school-like, accomplishment-driven pedagogies (e.g., music conservatory exams and grades), pre-existing differences may exert a larger influence than they would in cultures in which music learning and performance are more integrated into daily life. In many

\section{References}

Bialystok, E., and DePape, A. (2009). Musical expertise, bilingualism, and executive function. J. Exp. Psychol. Hum. 35, 565-574. doi: 10.1037/a0012735

Bilhartz, T. D., Bruhn, R. A., and Olson, J. E. (1999). The effect of early music training on child cognitive development. J. Appl. Dev. Psychol. 20, 615-636. doi: 10.1016/S0193-3973(99)00033-7

Bonneville-Roussy, A., Lavigne, G. L., and Vallerand, R. J. (2011). When passion leads to excellence: the case of musicians. Psychol. Music 39, 123-138. doi: $10.1177 / 0305735609352441$

Bouchard, T. J. Jr. (2004). Genetic influence on human psychological traits: a survey. Curr. Dir. Psychol. Sci. 13, 148-151. doi: 10.1111/j.0963-7214.2004.00295.x

Braver, T. S., and Cohen, J. D. (2000). "On the control of control: the role of dopamine in regulating prefrontal function and working memory," in Attention and Performance XVIII: Control of Cognitive Processes, eds S. Monsell and J. Driver (Cambridge, MA: MIT Press), 713-737.

Butkovic, A., Ullén, F., and Mosing, M. A. (2015). Personality related traits as predictors of music practice: underlying environmental and genetic influences. Pers. Individ. Dif. 74, 133-138. doi: 10.1016/j.paid.2014.10.006

Caspi, A., Roberts, B. W., and Shiner, R. L. (2005). Personality development: stability and change. Annu. Rev. Psychol. 56, 453-484. doi: 10.1146/annurev.psych.55.090902.141913

Corrigall, K. A., Schellenberg, E. G., and Misura, N. M. (2013). Music training, cognition, and personality. Front. Psychol. 4:222. doi: 10.3389/fpsyg.2013. 00222

Costa-Giomi, E. (1999). The effects of three years of piano instruction on children's cognitive development. J. Res. Music Educ. 47, 198-212. doi: 10.2307/3345779

Costa-Giomi, E. (2012). "Music instruction and children's intellectual development: the educational context of music participation," in Music, Health, and
non-Western cultures, music making is a culturally valued and frequent group activity in which all members of the group participate, such as in rituals or celebrations (Sloboda, 1988; Dunbar et al., 2012). In these contexts, variables such as SES, intelligence, and personality may play a much smaller role in influencing which individuals learn to play music.

Our findings highlight the need to consider predispositions when studying the potential benefits of environmental interventions such as music training. We do not deny that environmental effects play a role in any behavior, but a complete account requires consideration of genetics as well. In quasi-experimental and correlational studies, associations between music training and non-musical skills are likely to reflect gene-environment interactions rather than simple environmental effects (Schellenberg, 2015). In true experiments using random assignment to music lessons or a control group, inconsistent findings (Bilhartz et al., 1999; Costa-Giomi, 1999; Schellenberg, 2004; Moreno et al., 2009, 2011; Kaviani et al., 2014) may reflect the tendency for certain individuals - such as those who are high in opennessto-experience-to reap more benefit from stimulating environments. Future research on associations between music training and non-musical abilities in childhood should consider individual differences that pertain to parents (such as personality and cognitive ability) as well as those that pertain to children.

\section{Acknowledgments}

Supported by the Social Sciences and Humanities Research Council of Canada. Caterina Minaudo, Nicole Misura, and Monika Mankarious assisted in data collection.
Wellbeing, eds. R. A. R. MacDonald, G. Kreutz, and L. Mitchell (Oxford: Oxford University Press), 339-356.

Dai, D. Y., and Schader, R. (2001). Parents' reasons and motivations for supporting their child's music training. Roeper Rev. 24, 23-26. doi: 10.1080/02783190109554121

Deal, J. E., Halverson, C. F. Jr., Martin, R. P., and Baker, S. (2007). The inventory of children's individual differences: development and validation of a short version. J. Pers. Assess. 89, 162-166. doi: 10.1080/00223890701468550

Degé, F., Wehrum, S., Stark, R., and Schwarzer, G. (2014). Music lessons and academic self-concept in 12- to 14-year-old children. Music. Sci. 18, 203-215. doi: $10.1177 / 1029864914523283$

DeYoung, C. G., Cicchetti, D., Rogosch, F. A., Gray, J. R., Eastman, M., and Grigorenko, E. L. (2011). Sources of cognitive exploration: genetic variation in the prefrontal dopamine system predicts Openness/Intellect. J. Res. Pers. 45, 364-371. doi: 10.1016/j.jrp.2011.04.002

Dollinger, S. J., and Orf, L. A. (1991). Personality and performance in "personality": conscientiousness and openness. J. Res. Pers. 25, 276-284. doi: 10.1016/00926566(91)90020-Q

Drayna, D., Manichaikul, A., de Lange, M., Snieder, H., and Spector, T. (2001). Genetic correlates of musical pitch recognition in humans. Science 291, 1969-1972. doi: 10.1126/science.291.5510.1969

Dunbar, R. I. M., Kaskatis, K., MacDonald, I., and Barra, V. (2012). Performance of music elevates pain threshold and positive affect: implications for the evolutionary function of music. Evol. Psychol. 10, 688-702.

Dyce, J. A., and O'Connor, B. P. (1994). The personalities of popular musicians. Psychol. Music 22, 168-173. doi: 10.1177/0305735694222006

Ericsson, K. A., Krampe, R. T., and Tesch-Römer, C. (1993). The role of deliberate practice in the acquisition of expert performance. Psychol. Rev. 100, 363-406. doi: 10.1037/0033-295X.100.3.363 
Forgeard, M., Winner, E., Norton, A., and Schlaug, G. (2008). Practicing a musical instrument in childhood is associated with enhanced verbal ability and nonverbal reasoning. PLOS ONE 3:e3566. doi: 10.1371/journal.pone.00 03566

Furnham, A., Swami, V., Arteche, A., and Chamorro-Premuzic, T. (2008). Cognitive ability, learning approaches and personality correlates of general knowledge. Educ. Psychol. 28, 427-437. doi: 10.1080/01443410701727376

George, E. M., and Coch, D. (2011). Music training and working memory: an ERP study. Neuropsychologia 49, 1083-1094. doi: 10.1016/j.neuropsychologia.2011.02.001

Gillespie, W., and Myors, B. (2000). Personality of rock musicians. Psychol. Music 28, 154-165. doi: 10.1177/0305735600282004

Habib, M., and Besson, M. (2009). What do music training and musical experience teach us about brain plasticity? Music Percept. 26, 279-285. doi: 10.1525/mp.2009.26.3.279

Hambrick, D. Z., and Tucker-Dobb, E. M. (2015). The genetics of music accomplishment: evidence for gene-environment correlation and interaction. Psychon. Bull. Rev. 22, 112-120. doi: 10.3758/s13423-014-0671-9

Harris, J. A. (2004). Measured intelligence, achievement, openness to experience, and creativity. Pers. Individ. Dif. 36, 913-929. doi: 10.1016/S01918869(03)00161-2

Hille, A., and Schupp, J. (2014). How learning a musical instrument affects the development of skills. Econ. Educ. Rev. 44, 56-82. doi: 10.1016/j.econedurev.2014.10.007

Ho, Y.-C., Cheung, M.-C., and Chan, A. S. (2003). Music training improves verbal but not visual memory: cross-sectional and longitudinal explorations in children. Neuropsychology 17, 439-450. doi: 10.1037/0894-4105.17. 3.439

Hyde, K. L., Lerch, J., Norton, A., Forgeard, M., Winner, E., Evans, A. C., et al. (2009). Musical training shapes structural brain development. J. Neurosci. 29, 3019-3025. doi: 10.1523/JNEUROSCI.5118-08.2009

John, O. P., Donahue, E. M., and Kentle, R. L. (1991). The Big Five InventoryVersions $4 a$ and 54. Berkeley, CA: University of California, Berkeley, Institute of Personality and Social Research.

John, O. P., Naumann, L. P., and Soto, C. J. (2008). "Paradigm shift to the integrative big-five trait taxonomy: history, measurement, and conceptual Issues," in Handbook of Personality: Theory and Research, eds O. P. John, R. W. Robins, and L. A. Pervin (New York, NY: Guilford), 114-158.

Kaviani, H., Mirbaha, H., Pournaseh, M., and Sagan, O. (2014). Can music lessons increase the performance of preschool children in IQ tests? Cogn. Process. 15, 77-84. doi: 10.1007/s10339-013-0574-0

Macnamara, B. N., Hambrick, D. Z., and Oswald, F. L. (2014). Deliberate practice and performance in music, games, sports, education, and professions: a meta-analysis. Psychol. Sci. 25, 1608-1618. doi: 10.1177/09567976145 35810

Matthews, G., Deary, I. J., and Whiteman, M. C. (2003). Personality Traits. Cambridge, UK: Cambridge University Press. doi: 10.1017/CBO97805118 12736

McCrae, R. R. (1987). Creativity, divergent thinking, and openness to experience. J. Pers. Soc. Psychol. 52, 1258-1265. doi: 10.1037/0022-3514.52. 6.1258

McCrae, R. R. (1993). Openness to experience as a basic dimension of personality. Imag. Cogn. Pers. 13, 39-55. doi: 10.2190/H8H6-QYKR-KEU8-GAQ0

Mehr, S. A. (2014). Music in the home: new evidence for an intergenerational link. J. Res. Music Educ. 62, 78-88. doi: 10.1177/0022429413520008

Moradzadeh, L., Blumenthal, G., and Wiseheart, M. (2014). Musical training, bilingualism, and executive function: a closer look at task switching and dual-task performance. Cogn. Sci. doi: 10.1111/cogs.12183. [Epub ahead of print].

Moreno, S., Marques, C., Santos, A., Santos, M., Castro, S. L., and Besson, M. (2009). Musical training influences linguistic abilities in 8-year-old children: more evidence for brain plasticity. Cereb. Cortex 19, 712-723. doi: 10.1093/ cercor/bhn 120

Moreno, S., Bialystok, E., Barac, R., Schellenberg, E. G., Cepeda, N. J., and Chau, T. (2011). Short-term music training enhances verbal intelligence and executive function. Psychol. Sci. 22, 1425-1433. doi: 10.1177/0956797611 416999

Mosing, M. A., Madison, G., Pedersen, N. L., Kuja-Halkola, R., and Ullén, F. (2014). Practice does not make perfect: no causal effect of music practice on music ability. Psychol. Sci. 25, 1795-1803. doi: 10.1177/0956797614 541990

Moutafi, J., Furnham, A., and Crump, J. (2006). What facets of openness and conscientiousness predict fluid intelligence score? Learn. Individ. Dif. 16, 31-42. doi: 10.1016/j.lindif.2005.06.003

Müllensiefen, D., Gingras, B., Musil, J., and Stewart, L. (2014). The musicality of non-musicians: an index for assessing musical sophistication in the general population. PLoS ONE 9:e89642. doi: 10.1371/journal.pone.0101091

Norton, A., Winner, E., Cronin, K., Overy, K., Lee, D. J., and Schlaug, G. (2005). Are there pre-existing neural, cognitive, or motoric markers for musical ability? Brain Cogn. 59, 124-134. doi: 10.1016/j.bandc.2005.05.009

Panksepp, J. (1998). Affective Neuroscience: The Foundations of Human and Animal Emotions. New York, NY: Oxford University Press.

Park, H., Lee, S., Kim, H.-J., Ju, Y. S., Shin, J.-Y., Hong, D., et al. (2012). Comprehensive genomic analyses associate UGT8 variants with musical ability in Mongolian population. J. Med. Genet. 49, 747-752. doi: 10.1136/jmedgenet2012-101209

Penhune, V. B. (2011). Sensitive periods in human development: evidence from musical training. Cortex 47, 1126-1137. doi: 10.1016/j.cortex.2011.05.010

Plomin, R. (2014). Genotype-environment correlation in the era of DNA. Behav. Genet. 44, 629-638. doi: 10.1007/s10519-014-9673-7

Plomin, R., DeFries, J. C., and Loehlin, J. C. (1977). Genotype-environment interaction and correlation in the analysis of human behavior. Psychol. Bull. 84, 309-322. doi: 10.1037/0033-2909.84.2.309

Robbins, T. W. (2005). Chemistry of the mind: neurochemical modulation of prefrontal cortical function. J. Comp. Neurol. 493, 140-146. doi: 10.1002/cne.20717

Ruthsatz, J., Detterman, D., Griscom, W. S., and Cirullo, B. A. (2008). Becoming an expert in the musical domain: it takes more than just practice. Intelligence 36, 330-338. doi: 10.1016/j.intell.2007.08.003

Scarr, S., and McCartney, K. (1983). How people make their own environments: a theory of genotype $\rightarrow$ environment effects. Child Dev. 54, 424-435.

Schellenberg, E. G. (2004). Music lessons enhance IQ. Psychol. Sci. 15, 511-514. doi: 10.1111/j.0956-7976.2004.00711.x

Schellenberg, E. G. (2006). Long-term positive associations between music lessons and IQ. J Educ. Psychol. 98, 457-468. doi: 10.1037/0022-0663.98.2.457

Schellenberg, E. G. (2011a). Examining the association between music lessons and intelligence. Br. J. Psychol. 102, 283-302. doi: 10.1111/j.2044-8295.2010.02000.x

Schellenberg, E. G. (2011b). Music lessons, emotional intelligence, and IQ. Music Percept. 29, 185-194. doi: 10.1525/mp.2011.29.2.185

Schellenberg, E. G. (2015). Music training and speech perception: a geneenvironment interaction. Ann. N.Y. Acad. Sci. doi: 10.1111/nyas.12627. [Epub ahead of print].

Schellenberg, E. G., and Mankarious, M. (2012). Music training and emotion comprehension in childhood. Emotion 12, 887-891. doi: 10.1037/a0027971

Schellenberg, E. G., and Weiss, M. W. (2013). "Music and cognitive abilities", in The Psychology of Music, 3rd Edn., ed D. Deutsch (Amsterdam: Elsevier), 499-550.

Schultz, W. (2006). Behavioral theories and the neurophysiology of reward. Annu. Rev. Psychol. 57, 87-115. doi: 10.1146/annurev.psych.56.091103.070229

Sergeant, D., and Thatcher, G. (1974). Intelligence, social status and musical abilities. Psychol. Music 2, 32-57. doi: 10.1177/030573567422005

Sloboda, J. A. (ed.). (1988). Generative Processes in Music. Oxford: Oxford University Press.

Soto, C. J., John, O. P., Gosling, S. D., and Potter, J. (2008). The developmental psychometrics of big five self-reports: acquiescence, factor structure, coherence, and differentiation from ages 10 to 20. J. Pers. Soc. Psychol. 94, 718-737. doi: 10.1037/0022-3514.94.4.718

Strait, D., and Kraus, N. (2011). Playing music for a smarter ear: cognitive, perceptual, and neurobiological evidence. Music Percept. 29, 133-146. doi: 10.1525/mp.2011.29.2.133

Tan, Y. T., McPherson, G. E., Peretz, I., Berkovic, S. F., and Wilson, S. J. (2014). The genetic basis of music ability. Front. Psychol. 5:658. doi: 10.3389/fpsyg.2014.00658

Theorell, T., Lennartsson, A. K., Madison, G., Mosing, M. A., and Ullén, F. (2015). Predictors of continued playing or singing - from childhood and adolescence to adult years. Acta Paediatr. 104, 274-284. doi: 10.1111/apa.12870

Ukkola, L. T., Onkamo, P., Raijas, P., Karma, K., and Järvelä, I. (2009). Musical aptitude is associated with AVPR1A-haplotypes. PLoS ONE 4:e5534. doi: 10.1371/journal.pone.0005534 
Ukkola-Vuoti, L., Kanduri, C., Oikkonen, J., Buck, G., Blancher, C., Raijas, P., et al. (2013). Genome-wide copy number variation analysis in extended families and unrelated individuals characterized for musical aptitude and creativity in music. PLoS ONE 8:e56356. doi: 10.1371/journal.pone.00 56356

Wechsler, D. (1999). Wechsler Abbreviated Scale of Intelligence. San Antonio, TX: Psychological Corporation.

Conflict of Interest Statement: The Guest Associate Editor Franziska Degé declares that, despite having collaborated with author E. Glenn Schellenberg, the review process was handled objectively and no conflict of interest exists. The authors declare that the research was conducted in the absence of any commercial or financial relationships that could be construed as a potential conflict of interest.

Copyright (c) 2015 Corrigall and Schellenberg. This is an open-access article distributed under the terms of the Creative Commons Attribution License (CC BY). The use, distribution or reproduction in other forums is permitted, provided the original author(s) or licensor are credited and that the original publication in this journal is cited, in accordance with accepted academic practice. No use, distribution or reproduction is permitted which does not comply with these terms. 